\title{
Application of electrical Tomography for the hydrogeological study of the Fez-Taza corridor, Case of Bir Tam-Tam(Morocco)
}

\author{
Hassnae Faiz ${ }^{1, *}$, Anasse Benslimane ${ }^{1}$, Mohamed Chibout ${ }^{1,3}$, Mohamed El Mokhtar ${ }^{2,3}$, Fatima Zahra Faqihi $^{1}$, and Youssef \\ Chahid $^{1}$ \\ ${ }^{1}$ Laboratory Geosciences, Environment and Associated Resources, Faculty of Sciences Dhar El Mahraz, University Sidi Mohamed Ben \\ Abdellah, Fez, Morocco. \\ ${ }^{2}$ Laboratory of Geosciences, Faculty of Science, University Ibn Tofail, Kenitra, Morocco. \\ ${ }^{3}$ Society AFRICA GEO-SERVICES, Fez, Morocco.
}

\begin{abstract}
The present work contributes to the multidisciplinary geological, hydrogeological, and geophysical exploration of groundwater in the Bir Tam-Tam region of the Fez-Taza corridor. Our main objective is to release water resources in our study area to supply drinking water in the region and irrigation of agricultural areas. Potential zones are located at the Lias fracturing zones. This study is interested in understanding the hydrogeological context of the study area through geophysical methods such as Electrical Tomography. The comparison of geological data, Drilling data, and the interpretation of the results of electrical Tomography have made it possible to highlight the geoelectric levels likely to constitute a potential aquifer and to locate possible structural accidents (faults) affecting the dolomitic limestone formations of Lias that could drain groundwater.
\end{abstract}

\section{Introduction}

The need for water in the world is increasing more and more with time; the resolution of this problem is mainly based on the development of science and techniques for groundwater research.

The present work is part of a better knowledge of groundwater resources in the Fez-Taza corridor. Nondetailed hydrogeological studies characterize this region; hence the objective is to improve hydrogeological knowledge and assess the potential of groundwater resources in this area which covers a geographical area where the water demand is constantly growing, especially for drinking water supply DWS for Taza, irrigation, and industrial activities.

\section{General framework of the study area}

\subsection{Situation of the study area}

- From a regional point of view: the study area is located inside the Fez-Taza corridor (Fig.1). The boundaries of this corridor are defined in the North by the outcrop limit of the essentially marly formations belonging to the prerifain layers; in the West, the limit of the basin of FezMeknes. From the WSW to the ENE, the boundary of the continuous outcrops of the liasic limestone of the Middle Atlas joins towards the NE that of the pre-rifain layers [4]

- From a local point of view: The surface of the study area is located in Bir Tam-Tam, at an estimated distance as the crow flies, about $40 \mathrm{~km}$ ESE of the city of Fez, 30 $\mathrm{km} \mathrm{NE}$ of the city of Sefrou, $57 \mathrm{~km} \mathrm{SW}$ of the city of Taza and $11 \mathrm{~km} \mathrm{~S}$ of the dam of Idriss Premier. Bir TamTam is a commune of the province of Sefrou in the administrative region of Fez-Meknes in Morocco.

- From an administrative point of view: the study area is located in the Douar of Hmiddane in the rural commune of Bir Tam-Tam, province of Sefrou, region Fez-Meknes.

\subsection{Climatic context}

The Fez-Taza corridor is characterized by a rainfall regime that divides the year in two. The winter is rainy from November to April, and the summer is dry from June to September. Rainfall varies between $500 \mathrm{~mm}$ to the West and $700 \mathrm{~mm}$ to the east (Taza).

The average minimum temperatures vary between $11.1{ }^{\circ} \mathrm{C}$ (Fez, altitude $415 \mathrm{~m}$ ) and $11^{\circ} \mathrm{C}$ (Taza, altitude $510 \mathrm{~m}$ ); the average maximum temperatures are $24.6{ }^{\circ} \mathrm{C}$ in Fez and $24.1^{\circ} \mathrm{C}$ in Taza.

\subsection{Geological context}

The Fez-Taza corridor constitutes the most eastern part of the South Rifain furrow.

The sedimentary series in the Fez-Taza corridor essentially includes:

- Primary and Secondary: The Primary consists of shales and sandstones, sometimes metamorphic represented in several buttonholes, the most important of which is Jbel Tazzeka.

* Corresponding author: hassnae.faiz@gmail.com 


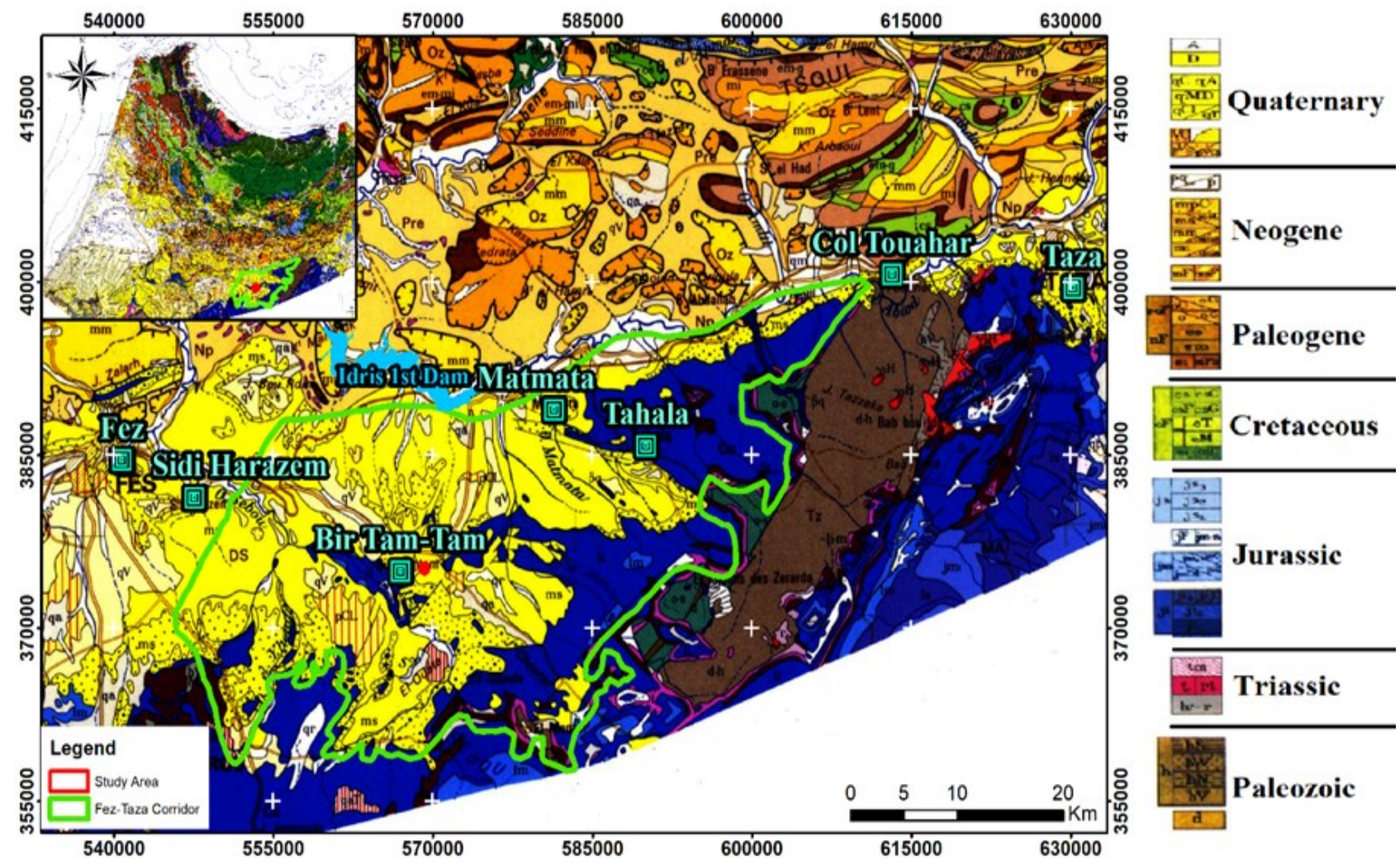

Fig. 1. a) Location map of the study area in the Fez-Meknes region, North of Morocco; b) Location map of the study area in the FezTaza corridor on the geological map of the Rif $1 / 500000$

Then comes a permo-triassic series of continental and lagoonal red marls, discordant on the Primary, often accompanied by doleritic basalt flows [7].

The limestones and dolomites of the Lias come practically in concordance on the Permo-Trias. A massive series constitute the Lower Lias; then comes the middle Lias in dolomitic limestones and limestones with flint and limestone or sub-lithographic limestones.

- Miocene-Pliocene: The transgressive Miocene was deposited on a Causse that emerged since the Jurassic (Domerian), eroded, folded, and fractured. Two primary levels are distinguished: at the base, the detrital Helvetian (sandstone and marlstone), then the essentially marly Tortonian, with fine marlstone intercalations (called blue marl series).

\subsection{Structural context}

This region has never undergone significant tectonic movements after the Hercynian phases. The only deformations observed are faults due to epirogenic movements that occurred during the Second and Tertiary periods.

From a hydrogeological point of view, it is important to know the deep tectonics of the limestone extensions of the Middle Atlas Causse under the Miocene cover of the Fez-Taza corridor Lias limestones constitute the reservoir that contains the main groundwater resources in this sector.

\section{Hydro-geophysical study by electrical Tomography}

In order to follow the hydrogeological characterization of the study area in the horizontal and vertical directions of the water reservoir in the Bir Tam-Tam sector, a geophysical campaign by electrical Tomography was carried out in the region.

- Principle of electrical Tomography:

Electrical Tomography allows obtaining an "electrical image" of the subsurface, i.e., a pseudo section of the apparent resistivity versus depth. Therefore, it is highlighted to obtain a basement model where resistivity distribution varies vertically and horizontally along with the profile [3].

- Measurements:

09 electrical tomography profiles distributed in the surface of the study area. (ARES II geoelectrical Equipment).

- Data processing by Res2Dinv software:

The values obtained in the field are apparent resistivities. From these values, we try to find the calculated thicknesses and resistivities of the different bodies present $[5,6]$.

The Res2Dinv software proceeds through the steps of the inversion method, which is displayed in (Fig. 3). 


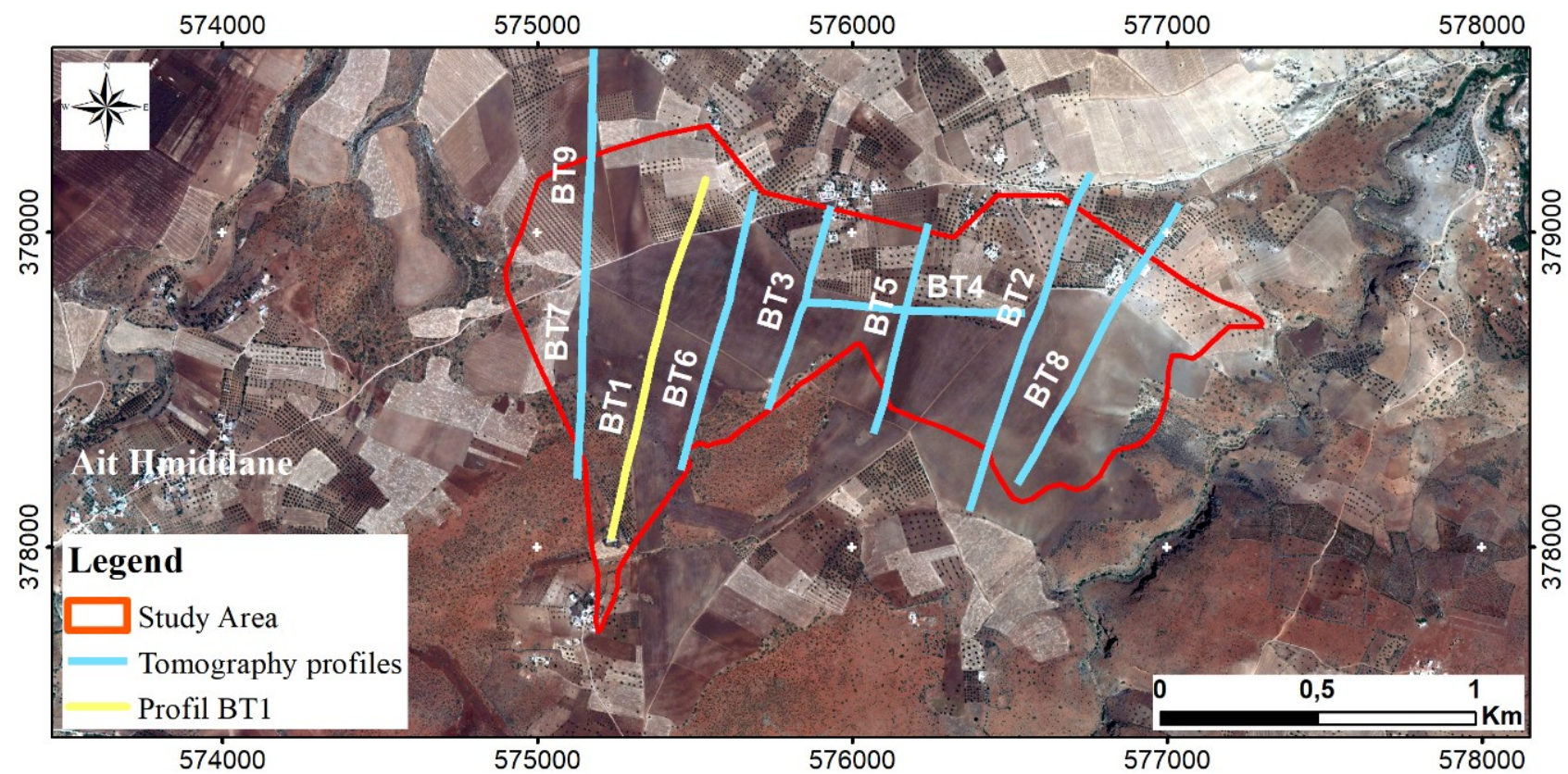

Fig. 2. Map of the location of Tomography profiles on the satellite image in the study area.
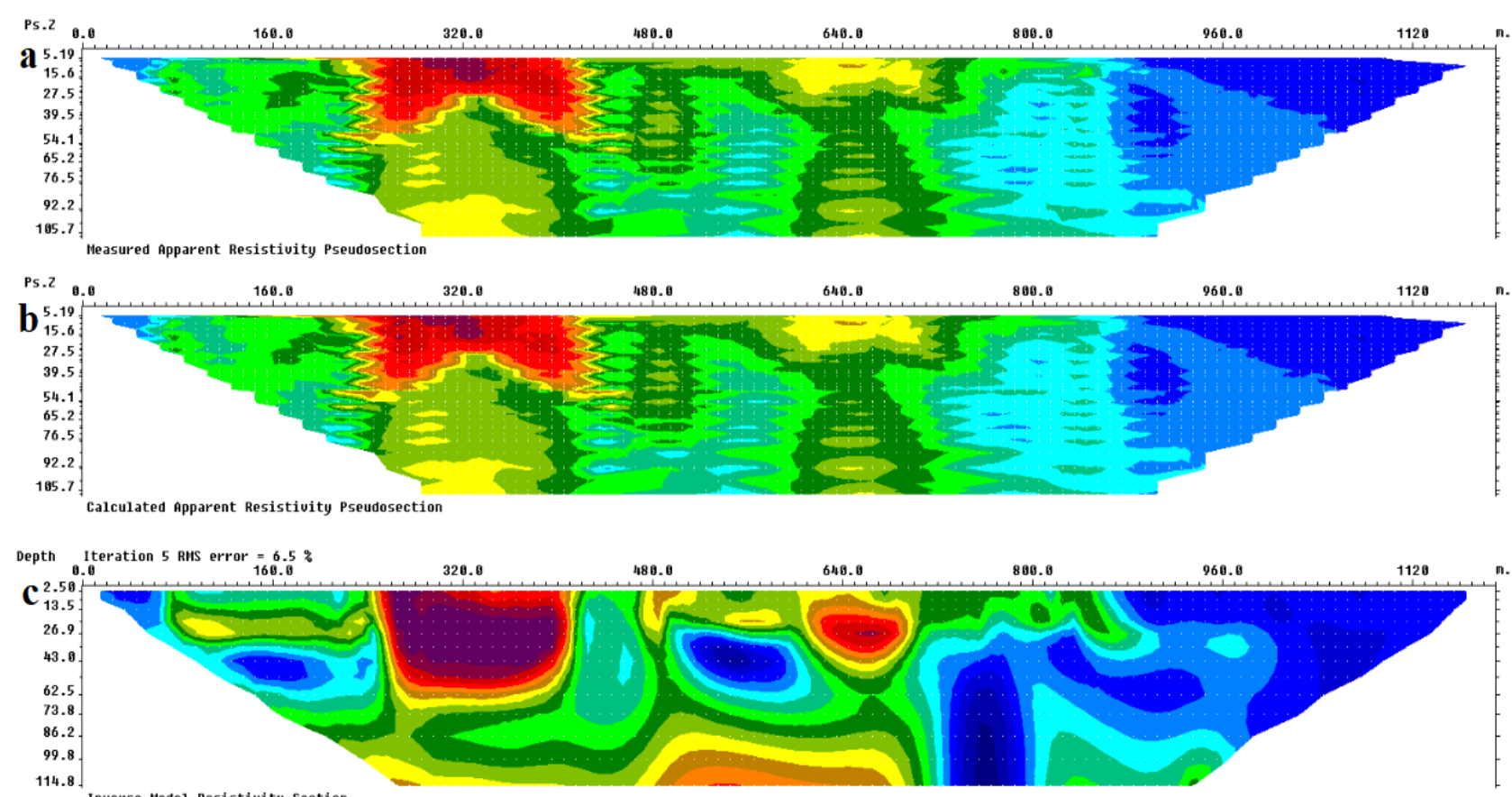

${ }_{8.14}^{\text {Inverse Mode1 Resistivity Section }} \prod_{18.8} \square_{43.3}^{99.9} \square_{531}^{238} \square_{1225} \square_{2824}$

Fig. 3. Vertical sections of resistivities versus depth: a) Measured Apparent Resistivity Pseudosection; b) Calculated Apparent Resistivity Pseudosection; c) Inverse Model Resistivity Section corresponding to the calculated apparent resistivity Pseudosection.

\section{Results and Discussions}

The analysis of the first pseudo-sections in resistivity of the electrical tomography profiles BT1, BT2, BT3, BT4, and BT5, proves the presence of four anomaly zones according to the value of the true resistivity and presented in the following order:

- Resistive zones:

- Resistant zone A: corresponds to dolomitic limestone formations of the Lias (resistivity varies from 250 to 1500 ohm.m);
- Resistant zone D: corresponds to lacustrine limestone formations of the Pliocene (resistivity varies from 250 to 2000 ohm.m). For values higher than 2000 ohm.m, they correspond to the karstified dolomitic limestone formations (voids).

- Intermediate zone B: corresponds to formations made up of sandy marl at the top and sandstone-conglomerate (Burdigalian) at the base of Miocene age (resistivity varies from 25 to $200 \mathrm{ohm} . \mathrm{m})$;

- Conductive zone C: corresponds to formations constituted by blue marls of Miocene age (resistivity varies from 3 to $20 \mathrm{ohm} . \mathrm{m})$. 


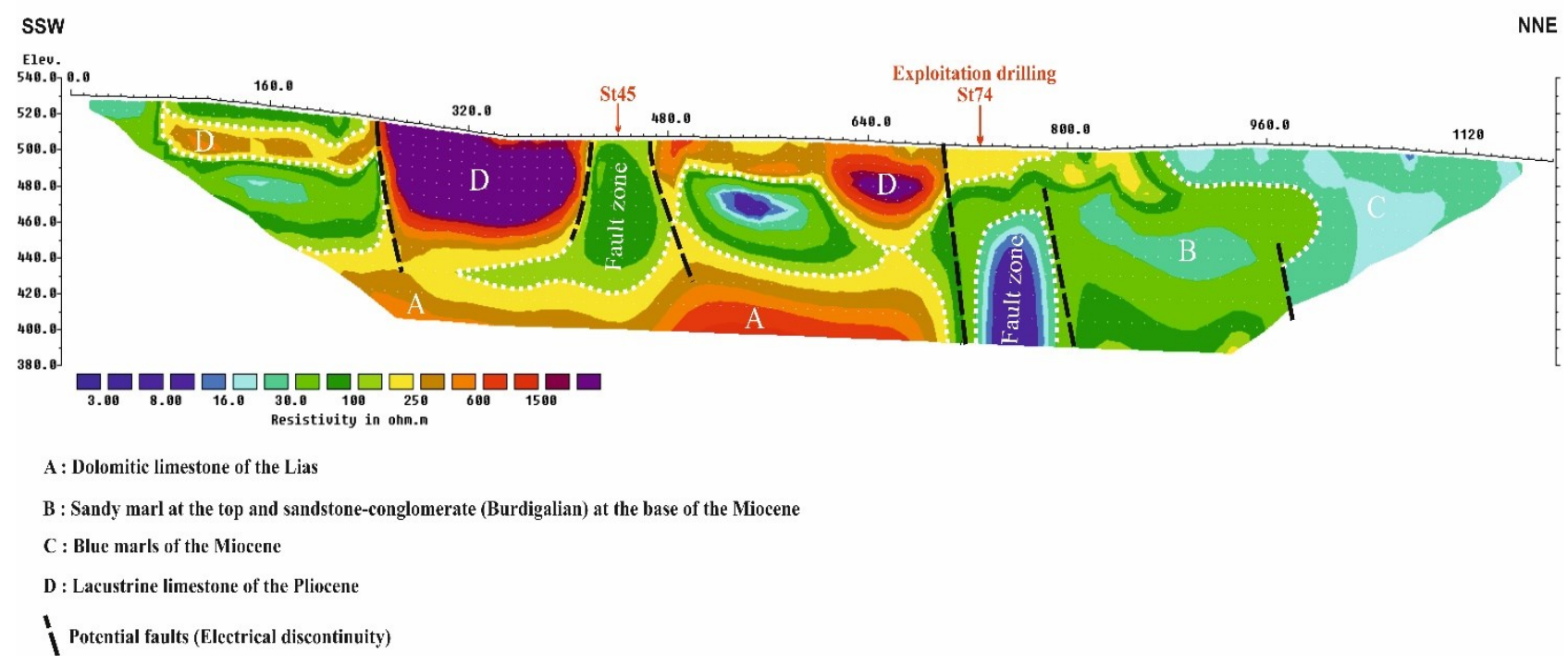

Fig. 4. 2D model of electrical resistivity distribution of the BT1 profile, with $10 \mathrm{~m}$ electrode spacing.

This pseudo-section shows the presence of 4 different formations mentioned in a vertical manner, which implies several electrical discontinuities of which two fault zones are well marked on the model (Fig. 4) (stations St45 and St74).

By analyzing the model, we also notice some electrical discontinuities that would probably correspond to faults that could represent targets for the location of future drillings for groundwater exploitation. Thus we were able to carry out the exploitation drilling $(\mathrm{Pt}=250 \mathrm{~m})$, which showed the presence of very fractured dolomite reaching a flow above 201/s.

\section{Conclusion}

The geological maps, the lithological sections of some existing drillings, and the GIS used for the geological identification of the different geoelectric levels are highlighted by the electric tomography profiles for the hydrogeological characterization of the study area.

The analysis of the 2D models affirms the presence of a conductive superficial terrain attributed to the blue marls of the Miocene, which surmounts the intermediate geoelectric level appropriate to the sandy marls. The whole deposited on a resistant formation corresponding to the dolomitic limestones of the Lias on the tomographic profiles we notice the presence of local resistant superficial zones corresponding to the lacustrine limestones of the Pliocene (anomaly zone).

The electrical tomography method is a powerful method that has allowed us to study and recognize our land and execute by the end of the drilling of exploitation with essential flows. Hence, the recommendation is to encourage more geophysical techniques and develop the methodology of electrical prospecting.

\section{References}

1. J. Astier, Geophysical applications in hydrogeology, Masson edict. Paris 275P (1971)

2. M. Chibout, A. Benslimane, M. El Mokhtar, F. Faqihi, S. M. El Kanti, A. Ntarmouchant, 2019. Geophysical Contribution to the Determination of the Limit between Laayoune and Foum El Oued Aquifers, Origin of Supply Sources of Oued Sakia El Hamra, Laayoune Province, Morocco. International Journal of Geosciences, (2019). https://doi.org/10.4236/ijg.2019.1011058

3. T. Dahlin, 2D resistivity surveying for environmental and engineering applications. First Break 14:275-283. (1996) https://doi.org/10.3997/1365-2397.1996014

4. O. Fassi Fihri et al. Hydrogeological study of the "Fez-Taza corridor". Karst Hydrology (Proceedings of Workshop W2 held at Rabat, Morocco, AprilMay 1997). IAHS Publ. no. 247, 1998.

5. M.H. Loke, Barker RD Rapid least-squares inversion of apparent resistivity pseudosections by a quasi-Newton method. Geophysics Prospect 44:131-152. (1996)

6. M.H. Loke, Tutorial: 2D and 3D electrical imaging surveys. (1996-2002)

7. A. Michard, Elements of Moroccan geology, Notes and memoirs of the geological service of Morocco252, 408. (1976). 